\title{
Transformaciones ocupacionales en la implementación del Acuerdo de Paz en un espacio territorial de capacitación y reincorporación para excombatientes: un estudio de caso
}

Occupational transformations for the implementation of the Peace Agreement in a territorial space for the reinsertion and training of former combatants: a case study

Transformações ocupacionais na implementação do Acordo de Paz em um espaço territorial de treinamento e reincorporação para excombatentes: um estudo de caso

\author{
Nidya Alejandra Jiménez Moreno ${ }^{1}$ \\ Martha Liliana Tunjo López ${ }^{2}$ \\ Edwin Julián Espitia Bello ${ }^{3}$ \\ Judy Jassbleidy Pinzón Porras ${ }^{4}$ \\ Laura María Ramírez Arias ${ }^{5}$
}

Recibido: 30 de abril 2019 • Enviado para modificación: 13 de diciembre 2019 • Aceptado: 24 de febrero 2020

Jiménez-Moreno, N.A., Tunjo-López, M.L., Espitia-Bello, E.J., Pinzón-Porras, J.J. y Ramírez-Arias, L.M. (2019). Transformaciones ocupacionales en la implementación del Acuerdo de Paz en un espacio territorial de capacitación y reincorporación para excombatientes: un estudio de caso. Revista Ocupación Humana, 19 (2), 51-72. https://doi.org/10.25214/25907816.233

\footnotetext{
${ }^{1}$ Terapeuta ocupacional. Magíster en Desarrollo Educativo y Social. Docente, Institución Universitaria Escuela Colombiana de Rehabilitación y Universidad Nacional de Colombia. Bogotá, Colombia. alejandrajimenezm@gmail.com iD https://orcid.org/0000-0003-2732-4921

2 Terapeuta ocupacional. Especialista en Administración en Salud Pública. Estudiante, Maestría en Desarrollo Educativo y Social, Universidad Pedagógica Nacional - CINDE. Secretaría Distrital de Salud de Bogotá. Bogotá, Colombia. totunjoliliana@gmail.com ID https://orcid.org/0000-0001-7494-3907

${ }^{3}$ Fonoaudiólogo. Magíster en Pedagogía para Educación Superior. Docente, Fundación Universitaria María Cano. Medellín, Colombia. edwinjulianespitiabello@fumc.edu.co iD https://orcid.org/0000-0002$\underline{3530-515 X}$

${ }^{4}$ Fonoaudióloga. Estudiante, Maestría en Patología del Habla y el Lenguaje, Universidad Especializada de las Américas. Hospital Universitario de la Samaritana. Bogotá, Colombia. Judhy123@gmail.com

(iD) https://orcid.org/0000-0001-6400-43

5 Terapeuta ocupacional. Estudiante, Maestría en Salud Mental Comunitaria, Universidad El Bosque. Centro de Educación Continua ASO.M.I.P. Quito, Ecuador. lauraramirez.to@gmail.com iD https://orcid.org/0000-0001-9227-1905
} 


\section{RESUMEN}

En noviembre de 2016 se firmó el Acuerdo Final para la Terminación del Conflicto y la Construcción de una Paz Estable y Duradera entre las Fuerzas Armadas Revolucionarias de Colombia - Ejército del Pueblo (FARC-EP) y el Gobierno Nacional de Colombia. Esto posibilitó a los integrantes de este grupo insurgente el tránsito a la vida civil y a la legalidad. El objetivo del estudio fue conocer cómo son y cómo se dan las transformaciones y reconfiguraciones ocupacionales y comunicativas de los excombatientes de las FARC-EP en su tránsito a la participación en la vida civil y política. Se recogieron narrativas de un grupo de excombatientes de las FARC-EP ubicados en un espacio territorial de capacitación y reincorporación, a través de observación participante, cartografía social y entrevistas. El análisis revela los retos de asumir la vida civil frente a nuevas interacciones, significados y formas de ocuparse en dos escenarios: la reconfiguración personal (identidad, cambios de rol, ajuste de rutinas, prácticas cotidianas y nuevos aprendizajes ocupacionales) y la reconfiguración social (expectativas de participación y reconocimiento, tensiones, reconciliaciones con su entorno y participación política). Se concluye que las transformaciones para la construcción de paz deben basarse en principios de justicia e inclusión social.

\section{PALABRAS CLAVE}

Terapia Ocupacional, paz, justicia social, guerrilla, integración social

\section{ABSTRACT}

In November 2016, the final Agreement for the End of the Conflict and the Construction of a Stable and Lasting Peace was signed between the Revolutionary Armed Forces of Colombia - People's Army (FARC-EP) and the National Government. This made it possible for the members of the insurgency to move on to civilian life and legality. The aim of this study is to find out which are the occupational and communicational transformations and reconfigurations of the former combatants of the FARC-EP, and how they happen in the transition to participation in civilian and political life. Narratives of a group of former combatants of the FARC-EP at the Territorial Space of Training and Reincorporation of the village La Cooperativa were collected through participant observation, social mapping and interviews. The analysis reveals the challenges of assuming civilian life in the face of new interactions, meanings and ways of dealing with it in two scenarios: personal reconfiguration (identity, role changes, adjustment of routines, daily practices and new occupational learning), and social reconfiguration (expectations of participation and recognition, tensions, reconciliation with their setting and political participation). The study concludes that the transformations for the construction of peace must be based on principles of justice and social inclusion.

\section{KEY WORDS}

Occupational Therapy, peace, social justice, guerrilla, social integration

\section{RESUMO}

Em novembro de 2016, a assinatura do acordo final para a terminação do conflito e construção de paz estável e durável foi feita entre guerrilha das FARC-EP (Forças Armadas Revolucionárias da Colômbia - Exército Popular (FARC-EP) e o Governo Nacional da Colômbia. Isto permitiu que os integrantes deste grupo insurgente, fizessem a transição para 
a vida civil e para a legalidade. O objetivo do estudo foi estabelecer, da maneira mais única e possível, as transformações e as reconfigurações ocupacionais e comunicativas dos ex-combatentes das FARC-EP e a transição para a vida civil e política. Narrativas de um grupo de ex-combatentes das FARC-EP, pertencentes ao Espaço Territorial de Treinamento e à Reincorporação da calçada Cooperativa, foram produzidas por meio da observação participante, do mapeamento social e de entrevistas. A análise revelou os desafios de assumir a vida civil diante de novas interações, significados e formas de lidar em dois cenários: reconfiguração pessoal (identidade, mudanças de papéis, ajustes da rotina, práticas cotidianas e novos aprendizes ocupacionais); e reconfiguração social (expectativas de participação e reconhecimento, tensão, reconciliação com o meio ambiente e participação política). Concluiu-se que as transformações para a construção da paz devem basear-se em princípios de justiça e inclusão social.

\section{PALAVRAS-CHAVE}

Terapia Ocupacional, paz, justiça social, guerrilha, integração social

\section{Introducción}

Luego de más de 60 años de confrontaciones dadas por el conflicto político y social en Colombia, en el año 2016 se firmó el Acuerdo de Paz entre la guerrilla de las Fuerzas Armadas Revolucionarias de Colombia - Ejército del Pueblo (FARC-EP) y el Gobierno Nacional, lo que permite transitar hacia el fin de la disputa armada del Estado con el grupo armado más antiguo de América Latina (Villamizar, 2018).

El conflicto armado en Colombia ha dejado graves heridas en su tejido social, entre ellas, la muerte de 218.094 colombianos entre 1958 y 2012, el $19 \%$ de ellos identificados como combatientes y el $81 \%$ como civiles. Además, ha dejado 5.712 .506 víctimas de desplazamiento forzado, afectando las dinámicas e interacciones económicas, políticas y culturales de comunidades campesinas, indígenas, afrocolombianas, movimientos sociales, líderes políticos y comunitarios, niños, mujeres, empresarios (Centro Nacional de Memoria Histórica, 2013,).

Colombia ha enfrentado varios ciclos que oscilan entre intenciones de cese a la confrontación armada y luchas por la ocupación del territorio entre grupos insurgentes y el Estado. Así, como lo refiere el Instituto Distrital de la Participación y Acción Comunal (IDPAC, 2019), ha habido varios intentos por gozar de una Colombia en paz; desde 1981 a la actualidad se han declarado y materializado formalmente alternativas para hacer viable el cese a la confrontación, como se muestra en la figura 1.

Desde octubre del año 2012 se inició la fase del fin del conflicto, con nuevos espacios para los diálogos de paz entre el Gobierno Nacional y la guerriIla de las FARC-EP en La Habana, Cuba. Estos diálogos desarrollaron cinco puntos centrales: desarrollo agrario integral; participación política de los desmovili- 
Figura 1. Línea de tiempo de procesos de paz en Colombia 1981 - 2016.

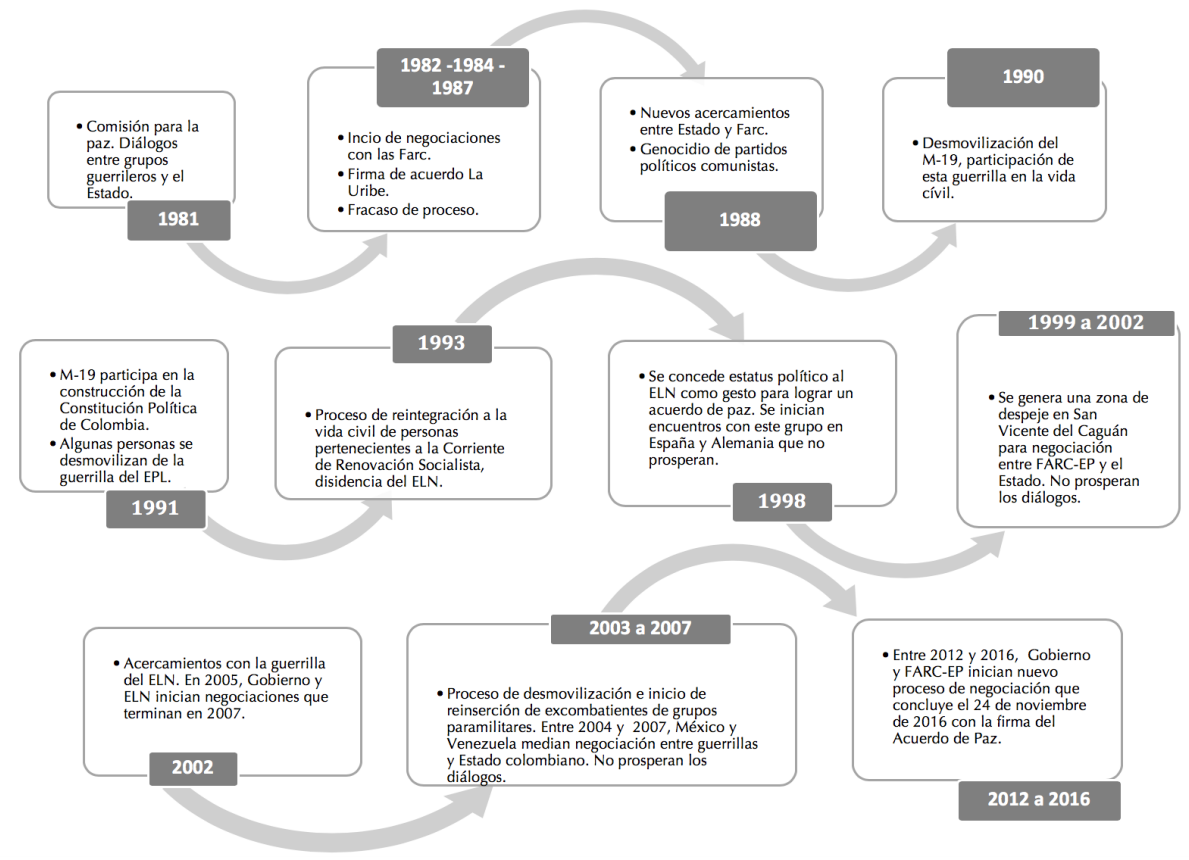

Fuente: elaboración propia a partir de información del Instituto Distrital de la Participación y Acción Comunal (IDPAC, 2019).

zados; fin del conflicto armado interno y desarme; fin del narcotráfico, y reparación integral de las víctimas del conflicto (Jiménez y Arboleda, 2018). Con esto, se propuso transformar la violencia por un camino de construcción de paz para la vida en los territorios.

Los momentos señalados en la figura 1 dejan ver que el Acuerdo de Paz enfrenta grandes desafíos, como afianzar la credibilidad, la legitimidad y la gobernabilidad para la paz; lograr la efectividad en el proceso de reintegración de excombatientes; avanzar en procesos de verdad, reconciliación y garantías de no repetición; establecer una gobernanza para la paz, y fortalecer la cultura de paz (Álvarez, 2017).
El término paz, utilizado en este artículo, es multifacético. Tal y como se define en la Constitución Política de Colombia de 1991 (llamada la Constitución para la Paz), la paz es un valor (protección, ordenamiento, libertad), es un derecho fundamental (bienestar subjetivo y colectivo, humanidad) y es un deber constitucional (corresponsabilidades, garantías de vida) (Asamblea Nacional Constituyente, 1991). Esto significa que Colombia asume la paz como estado ideal y como principio, desde la perspectiva de derecho fundamental y colectivo (Moreno, 2014).

Para la Fundación Cultura Democrática (Villagra, 2015), luego de un trabajo 
realizado en varias regiones del país impactadas por la violencia como Barrancabermeja, Cali, Medellín, Pasto, Sucre y Tibú, la paz es una nueva ciudadanía que goza de una cultura activa y crítica de participación desde las comunidades, con una dimensión de lo público a partir de la justicia social y la garantía de los derechos fundamentales; por ello, es clave el reconocimiento de lo colectivo y del territorio. Así pues, la paz está basada en la verdad, el perdón y la equidad, y debe ser vista más allá de la negociación del conflicto armado y la dejación de las armas, como un proceso asociado a cambios estructurales (en el ideal de un desarrollo social y humano sostenible) y a la garantía de otros derechos como la educación, la salud, el empleo y la no repetición de hechos de violencia.

Según Cortés, el Acuerdo de Paz plantea para Colombia un horizonte con amplias perspectivas, que pone en un nivel importante a la justicia social; es decir, "la paz por medio del derecho" (2016, p.40) no es una paz utópica y supera la mirada estrecha de poner solo fin a la violencia directa, porque propende por un nuevo orden político que se basa en dar valor real a la vida, a la justicia y a la seguridad. Es un proceso de oportunidades, especialmente para quienes han gozado muy poco de circunstancias de bienestar personal y colectivo (Díaz, 2015). En este mismo sentido, Prada et al. (2017) refieren que el proceso de paz es posible en la medida que se genere un importante acompañamiento y garantía en el abordaje de dimensiones personales, psicosociales, familiares, comunitarias, en salud, educativas, ciudadanas, en seguridad y productividad para las personas y los territorios que han estado implicados en la guerra.
Entonces, la paz implica una transformación multidimensional en la que emerge la reconfiguración de ocupaciones, formas de vida y otras posibilidades de participación social para quienes han estado involucrados en la confrontación (Peñas, et al., 2015). En esta medida, las FARC-EP, según los cinco aspectos centrales de la negociación, asumen la participación política como una ocupación pública, democrática y liberal. Sin embargo, dada la escasez de intervenciones basadas en evidencia y diseñadas específicamente para excombatientes, es crucial comprender las tensiones y expectativas ocupacionales desde la perspectiva de estas personas en su tránsito de la vida en clandestinidad a la vida civil y pública (Báez et al., 2019).

Con esto en mente, el presente estudio de caso tuvo como objetivo conocer cómo son y cómo se dan las transformaciones y reconfiguraciones ocupacionales y comunicativas de excombatientes de las FARC-EP en su tránsito a la participación en la vida civil y política, en el marco de principios de justicia e inclusión social, con miras a dilucidar aspectos específicos del cambio de vida que experimentan.

\section{Metodología}

Este estudio de caso surgió de discusiones académicas de profesores y estudiantes de Terapia Ocupacional y Fonoaudiología, participantes de los semilleros de investigación Ocuparte y Diversitas de la Institución Universitaria Escuela Colombiana de Rehabilitación - ECR, en un recorrido por temas de justicia, derechos humanos e inclusión social, en el contexto del proceso de implementación del 
Acuerdo de Paz que atraviesa el país. Así, el interés principal fue generar un acercamiento y evidencia para repensar las nuevas formas de ocuparse y comunicarse (el cómo, cuándo, dónde, y las garantías de estos procesos) de los excombatientes de las FARC-EP, uno de los actores sociales relevantes del conflicto armado y, ahora, del proceso de paz.

Para ello, y desde la participación de la Escuela Colombiana de Rehabilitación en la Red Saludpaz, se llevó a cabo una visita al Espacio Territorial de Capacitación y Reincorporación (ETCR) Georgina Ortiz ${ }^{6}$ durante los días 19, 20 y 21 de agosto de 2017. Este espacio territorial está ubicado en la vereda La Cooperativa, a dos horas y media del casco urbano del municipio de Vista Hermosa, en el departamento de Meta.

El desarrollo de este estudio de caso permitió el acercamiento a una realidad particular. Como lo afirma el Sector de Conocimiento y Aprendizaje del Banco Interamericano de DesarroIlo (2011), este método hace posible explicitar el conocimiento a partir de la reconstrucción de una experiencia y la interpretación crítica de lo sucedido, tomando en cuenta las lecciones aprendidas como insumo clave para la toma de decisiones y la proyección de nuevas investigaciones y acciones para el progreso humano y social.

Para realizar el estudio se contó inicialmente con el aval y la autorización del líder encargado del espacio territorial; luego, la propuesta fue socializada con los integrantes de este, quienes manifestaron su interés en participar y dieron verbalmente su consentimiento informado. También se les informó sobre el manejo confidencial de la información. En un primer momento se pensó que sería difícil acceder a sus relatos y compartir con ellos, por el contrario, se mostraron receptivos, colaboradores y empáticos durante la visita.

Como herramientas exploratorias se usaron la observación participante y entrevistas semiestructuradas. En cuanto a la observación participante, se realizó un ejercicio de inmersión en el espacio territorial, compartiendo con sus habitantes las actividades diarias: alimentación, cuidado del entorno, capacitación, actividades instrumentales, descanso. Estas experiencias se registraron en un diario de campo, donde se consignó lo observado, lo escuchado, lo conversado y lo vivido.

También, como producto de la interacción entre los integrantes del espacio territorial y el equipo de investigación, se hizo una cartografía. Se trató de un ejercicio participativo para reconocer y reconstruir, a través de una propuesta de mapa social, las experiencias vividas en ese territorio, las actividades realizadas, las relaciones, los actores sociales, las instituciones, así como los espacios físicos, simbólicos y geográficos representativos.

La guía para las entrevistas semiestructuradas fue diseñada por el equipo de investigadores y se sometió a revisión de expertos en temas de desarrollo social, comunicación y ocupación, y de dos líderes del espacio territorial. Se contemplaron aspectos relacionados con la identidad, la vida cotidiana en condición de insurgencia versus la vida cotidiana

${ }^{6}$ El nombre de Georgina Ortiz se otorgó en honor a la primera mujer guerrillera muerta en combate por las disputas en Marquetalia (Líder del ETCR, comunicación personal, agosto de 2017). 
en el tránsito a la vida civil, y la participación política legal como horizonte ocupacional (tabla 1). El equipo de investigadores entrevistó a cinco participantes voluntarios, tres hombres y dos mujeres, quienes dieron su consentimiento verbal al proceso investigativo.
Además de los diarios de campo, la información se registró en grabaciones de audio, escritos y fotografías, previa autorización de los participantes. Los audios fueron transcritos por los investigadores para dar paso al análisis.

Tabla 1. Preguntas contempladas en la guía de entrevista semiestructurada.

\begin{tabular}{|l|l|}
\hline Aspecto & Preguntas orientadoras \\
\hline Identidad & ¿Quién es usted, cómo se describe? (nombre, edad, oficio, características de género, \\
& físicas, emocionales). \\
& ¿Qué ha cambiado en usted luego de la llegada al ETCR? \\
& ¿Qué es lo que más recuerda de la vida insurgente y por qué? \\
¿Qué lo caracteriza y lo diferencia de sus compañeros (cualidades, expresiones, \\
rasgos)? \\
Familia, iqué es y quiénes son para usted? Antes del ingreso a la guerrilla, ¿cómo era \\
su familia? \\
¿Qué es la guerrilla para usted?
\end{tabular}

Fuente: elaboración propia.

Se llevó a cabo el análisis de contenido de la información recolectada, categorizándola en una matriz diseñada por los investigadores y que contemplaba los tres aspectos considerados en la entrevista. Se tuvieron en cuenta los patrones significativos y recurrentes, y las perspectivas en expresiones y simbologías, los cuales dejaban ver los cambios, las transformaciones y las reconfiguraciones en las prácticas ocupacionales y, por ende, de las interacciones comunicativas. 


\section{Estudio de Caso}

\section{El proceso identitario}

En el territorio. La vereda La Cooperativa se ubica en el municipio de Vista Hermosa, departamento de Meta (figura 2). Es una región situada al sur oriente del país, con una superficie geográfica de $4.084 \mathrm{~km}^{2}$ y una temperatura media de $28^{\circ} \mathrm{C}$. Cuenta con una población aproximada de 499 habitantes, $58,72 \%$ hombres y $41,28 \%$ mujeres (Alcaldía Vistahermosa, s.f.).
Las vías de acceso se encuentran en mal estado, lo que en tiempos de lluvias provoca dificultades para la movilidad, el tránsito de productos y el ingreso de apoyo estatal. De acuerdo con uno de los líderes del Espacio Territorial de Capacitación y Reincorporación Georgina Ortiz, parte de las vías terciarias existentes en la región fueron construidas por los grupos insurgentes como apoyo a las comunidades y a las actividades de la estructura guerrillera. Vista Hermosa cuenta con equipamientos

Figura 2. Ubicación de la vereda La Cooperativa.



Fuente: tomado de Equipo Humanitario Colombia (2016).

de uso público como instituciones educativas, espacios recreo-deportivos, un centro de salud de primer nivel, una institución prestadora de servicios de salud (IPS) privada, una biblioteca municipal y una casa cultural. Estos espacios ofrecen servicios a la comunidad, no obstante, no son suficientes para cubrir las demandas del municipio y sus zonas aledañas (Alcaldía de Vista Hermosa et al., 2014). La representación gráfica del municipio, elaborada por quienes participaron en el ejercicio de cartografía social, se muestra en la figura 3. 
Figura 3. Mapa de Vistahermosa elaborado por excombatientes.

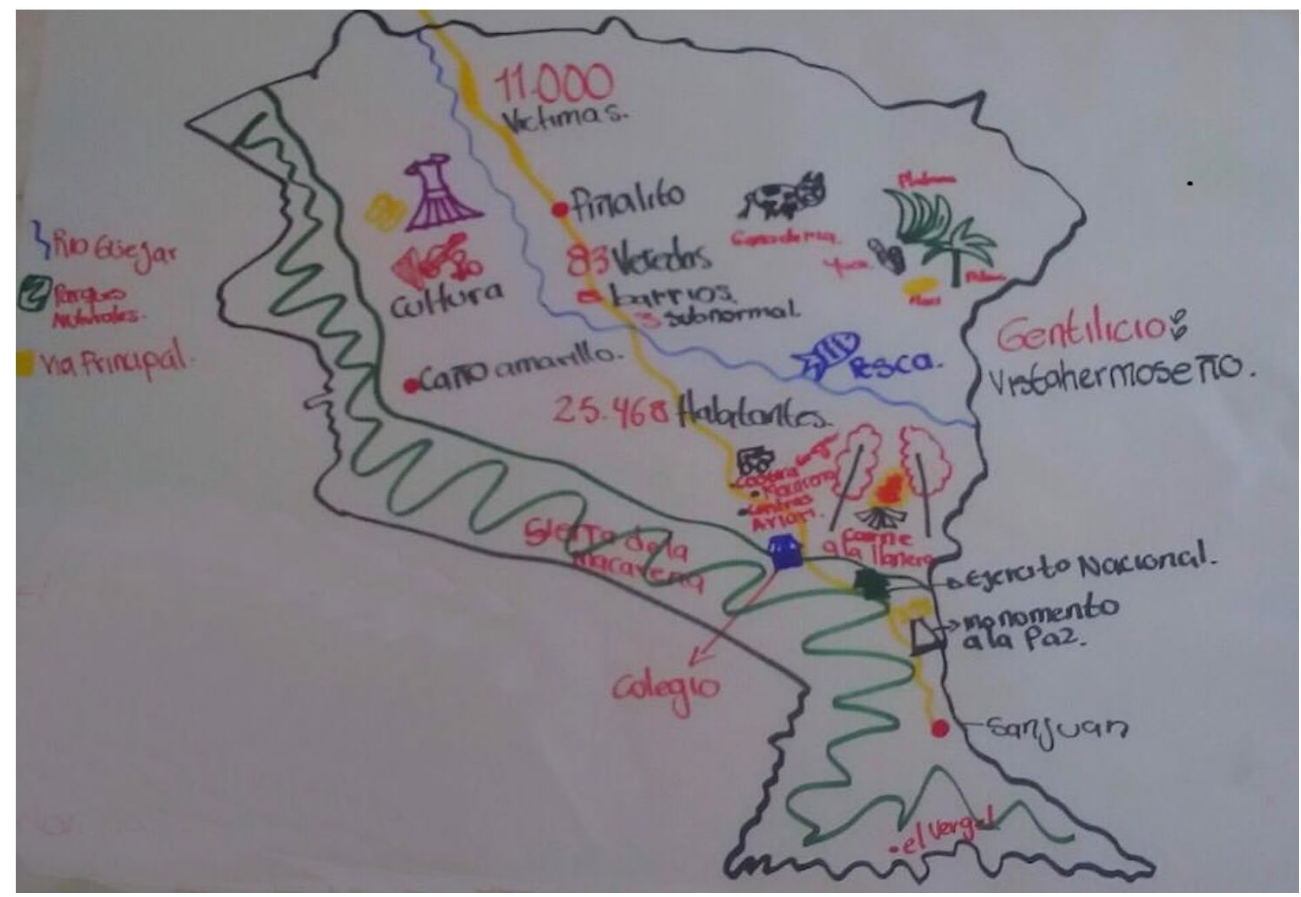

Fuente: ejercicio de cartografía social (20 de agosto de 2017).

Dentro de la historia del conflicto en Colombia, este territorio ha tenido un papel protagónico por permitir el paso a zonas del piedemonte amazónico y haber sido uno de los principales productores de coca. Así mismo, durante los diálogos de paz entre la guerrilla de las FARC-EP y el Gobierno Nacional en 1998, sirvió como zona de despeje junto con los municipios de La Uribe, Mesetas y La Macarena. Este hecho ha sido catalogado por algunas personas como la oportunidad para la expansión y el auge de las fuerzas guerrilleras, que luego justificó la implementación de acciones para reducir la presencia insurgente en el territorio (Medina, 2010).

Para ingresar al espacio territorial y realizar la visita prevista para este estudio fue necesario realizar un registro ante la
Policía Nacional, entidad encargada de custodiar y brindar condiciones de seguridad a todas las personas (incluso a los excombatientes de las FARC-EP), circunstancia que unos años atrás era totalmente inimaginable. Así pues, hubo lineamientos claros para la seguridad, el grupo de excombatientes estuvo atento a la visita y el líder a cargo del espacio territorial fue quien recibió al equipo de investigación. Luego de exponer el interés por dinamizar reflexiones en torno al proceso de paz, se autorizó la entrada al territorio.

En las personas. La identidad se constituye a partir de la inmersión y la interacción de las personas con otras en un mundo social. La relación con otros da lugar a la construcción de lo simbólico, de valores, expresiones y sentidos. Por 
lo tanto, la identidad se configura también con ideas basadas en la ocupación y la comunicación, estas proveen un contexto de interacciones y significados (Sanabria y Rubio, 2011). Christiansen (citado por Sanabria y Rubio, 2011) afirma que la identidad está estrechamente relacionada con lo que se hace y con las interpretaciones de aquellas acciones en el contexto de las relaciones con los demás. En este sentido, y según lo referido por los excombatientes del espacio territorial, las FARC-EP se reconocían como un colectivo, bajo una estructura político militar que surgió como respuesta a la agresión iniciada contra las colonias de Marquetalia, El Pato, Riochiquito y El Guayabero. Este grupo de personas al margen de la ley manifestaban, a través de la respuesta armada, su inconformidad y rebeldía frente a los intereses que impactaban negativamente la vida, principalmente del campo, dando paso a la lucha por el reconocimiento del campesinado como sujeto histórico y político en Colombia. Refieren que su primera declaración política se conoce como Programa Agrario de los Guerrilleros, en el cual se expresa que se alzan en armas porque ven cerradas las vías de la lucha política legal, pacífica y democrática (FARC-EP, s.f.a).

También expresan que el sentido de colectividad y comunidad que construyeron por años se conserva. Entendiendo que la comunidad es un compartir de experiencias habituales, donde existen la interdependencia y los significados compartidos (Townsend, citado por Cetina et al, 2017), puede afirmarse que esta se instaló como un proceso identitario y de estilo de vida. Si bien también han empezado a pensar en proyectos individuales, esperan mantener su identidad como grupo, pues sus lazos y redes están principalmente allí.
De esta manera, el lenguaje sigue siendo en plural. Las formas comunicativas de interacción dejaron ver la relevancia de la colectividad a través del uso de expresiones como todos vamos, estamos aprendiendo, creemos, haremos, estaremos juntos, decidiremos, hablaremos, consultaremos, iniciaremos. Estas son maneras de representar el mundo simbólico, los valores y creencias como grupo. Así mismo, en términos de la comunicación, señalan que fue importante darse cuenta de que ya no tiene mucho sentido manejar códigos, claves y señales que solo comprendían al interior del grupo y que empleaban en actividades al margen de la ley. Afirman, entonces, que su paso a la vida civil les compromete a transformar sus acciones y a dinamizar formas de adaptación a los contextos y realidades actuales.

Es así como, al comprenderse en una nueva identidad como ciudadanos, es decir, con derechos y deberes civiles (Prada et al., 2017), también se encuentran con transformaciones en sus identidades individuales, por ejemplo, sus nombres. Por cuestiones de seguridad, durante mucho tiempo fueron llamados por un alias o nombre político. Algunas personas del grupo comentan que no recordaban su nombre de nacimiento; según ellas, ha sido un descubrimiento reencontrarse con sus vidas antes de hacer parte del grupo guerrillero. Ha sido un ejercicio de memoria sobre sus familias, sus orígenes y sus historias de vida en aspectos que nunca se habían revelado.

Explorarse cara a cara a sí mismos y a los demás, sin la mediación de elementos de protección del rostro, ha sido, según ellos, revelar miradas y rasgos físicos que se ocultaron por supervivencia durante muchos años. Para algunos, haber sido 
parte del conflicto no fue una opción y con ello se desdibujaron elementos propios de su origen (familia, gustos iniciales, identificar y vivir etapas del transcurrir vital). Esto ha significado una comprensión de sí mismos, de sus cuerpos y subjetividades, dando lugar a otras expresiones y exposiciones, como el miedo, la alegría y el reencuentro. Como lo refiere Alvarado (2016), sin ser más que lo que sucedía en el día a día, las tácticas de supervivencia y el conflicto armado les negaron sus propias vidas a varias generaciones de niños, niñas y jóvenes.

Su subjetividad, tal y como lo refieren, se ha transformado; hay un lugar más claro para su propio pensar, sentir y actuar, pues ya no obedecen fielmente a la estructura del grupo guerrillero, con unas ideologías y operaciones inquebrantables. Ahora sus actos se dan también por sus propios intereses y necesidades. Señalaron que sus comprensiones personales de la realidad se transforman en la medida en que se van acomodando a la vida civil y van explorando las capacidades, gustos, inquietudes, nuevos haceres y realidades que vive un ciudadano del común.

Otro hallazgo relevante tiene que ver con la identificación con el territorio; según como lo representan, este tiene símbolos materiales e inmateriales, lugares y recorridos por los que ha transitado la vida y la confrontación. Refieren conocer y recordar corredores geográficos con exactitud, la selva y el monte fueron sus espacios de lucha, resistencia y sacrificio. El territorio es, entonces, ese lugar de búsqueda de sí mismo, ocupar espacios tiene que ver con sostener la identidad y la pertenencia (Palacios, 2016). Varios espacios rurales, dicen, tienen una importante historia de su presencia; sin mayores detalles, comentan del liderazgo, el orden social establecido, la organización de los espacios físicos y las relaciones construidas con las personas y las instituciones (algunas tensas, pero otras con satisfacción de justicia social).

Entonces, para los excombatientes, referirse actualmente a un proceso identitario significa reconocerse, sentirse parte de, transformarse para estar y pertenecer, reto para la reintegración social; pues es un proceso que no se da solo por su voluntad, sino que significa, de manera estructural, construir una propuesta política y social basada en el derecho a la paz. Como lo señala Christiansen (1999), la identidad es esencial para la vida social porque proporciona un contexto que permite derivar significados de experiencias diarias e interpretar la vida a lo largo del tiempo, así mismo, proporciona un marco para establecer objetivos y motivaciones de vida que contribuyen a la coherencia y al bienestar personal y colectivo.

\section{Transformaciones y reconfiguraciones en el transcurrir de la vida cotidiana}

La vida cotidiana es entendida como aquello que pasa todos los días, que sucede en el día a día, es el modo habitual de existir y estar en el mundo, es la forma frecuente y familiar con la que se está, incluso sin ser consciente de ello. Es una expresión fáctica de la vida misma y, en esa medida, contribuye a estructurar el comportamiento humano en actividades y tiempos. Genera sensaciones de comodidad, porque se vuelve una expresión del hacer en la vida totalmente natural, ubicada en un espacio y tiempo contextual (Uscatescu, 2001). De esta forma, vale la pena, en primer lugar, referir cómo era la estructura orgánica del grupo guerrillero, para luego comprender las prácticas coti- 
dianas. Según el relato del líder del espacio territorial, se entendía como se muestra en la figura 4.

La organización social comprendía una estructura vertical, estricta y jerárquica, donde el Estado Mayor Central era la principal instancia ideológica de las FARC-EP. Enseguida, el Secretariado era el encargado de la formación política, militar y táctica para las campañas desarrolladas en los territorios. Los líderes de bloque, por su parte, eran quienes concretaban los operativos y definían las prácticas en contexto; estos bloques estaban divididos por regiones del país (central, oriental, caribe, sur, etc.) y contaban con una organización interna de seguridad. Cada bloque tenía un representante ante el Secretariado (comuni- cación personal, Líder del ETCR, agosto de 2017).

La Conferencia Nacional Guerrillera era una instancia de encuentro para los representantes de bloque, en la cual se socializaba lo que ocurría en los territorios. Sin embargo, lo que de allí se definiera debía ser emitido por el Estado Mayor Central. Columnas, compañías, guerrillas y escuadras eran instancias menores en términos de toma de decisiones, internamente contaban con una organización en responsabilidades y roles, y debían seguir las directrices de mando del frente, el bloque y el Secretariado. Una escuadra, por último, era la unidad básica de organización; estaba conformada por doce personas. A su vez, una guerrilla estaba compuesta de dos escuadras; una compañía,

Figura 4. Estructura de organización social de las FARC-EP.

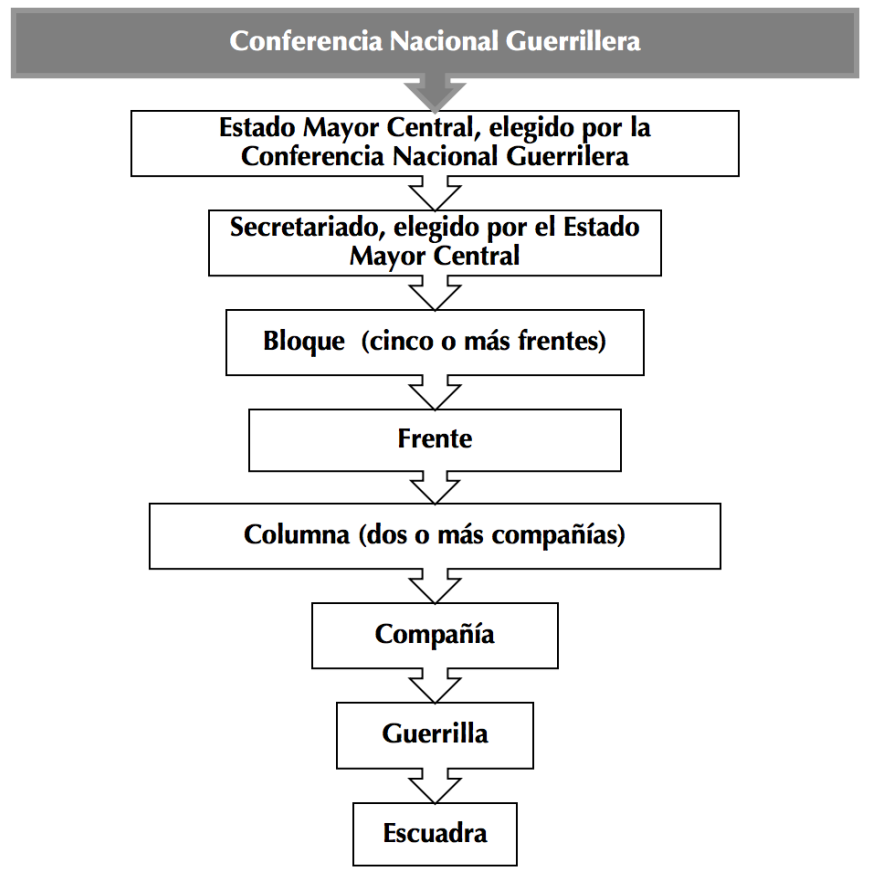

Fuente: elaboración propia a partir del relato del líder del Espacio Territorial de Capacitación y Reincorporación Georgina Ortiz (agosto de 2017). 
por dos guerrillas; una columna son dos compañías, y un frente, más de una columna (FARC-EP, s.f.b)

El grupo del espacio territorial compartió que la dinámica al interior del colectivo era rutinaria, iniciando el día a temprana hora y terminando tarde en la noche, se turnaban para hacer guardia y cuidar los campamentos; eran grupos de personas transitando la selva y los campos colombianos por largos periodos de tiempo, se consideraban nómadas. Se mantenían en constante elaboración de estrategias para salvaguardar sus vidas y atacar a quienes consideraban enemigos. La disciplina y la formación política siempre fueron parte de las actividades diarias. La vida era totalmente activa, con largos periodos de vigilia y trabajo. También, Ilevaban a cabo acciones para lograr mayor cercanía con la población civil y, con ello, favorecer las operaciones en los territorios, tanto para el trabajo político como en el apoyo logístico para la consecución de elementos necesarios en la operación; estas actividades eran monitoreadas por los responsables de cada escuadra, columna o frente.

A partir de la firma del Acuerdo de Paz, la organización en espacios de capacitación y reincorporación temprana ha pretendido facilitar las fases iniciales de adaptación de los miembros de las FARCEP a la vida civil. Estos espacios también han sido una oportunidad para acercar la oferta pública a la población que está en el territorio, incluyendo a los excombatientes (Prada et al., 2017).

De acuerdo con sus relatos, los integrantes del espacio territorial han tenido que repensar sus actividades, rutinas, roles, ritmos y organización; dicen haber experimentado allí una vida en calma. No obstante, refieren que la convivencia entre 316 personas, 92 mujeres y 220 hombres, quienes antes operaban en seis diferentes frentes, no se conocían y no habían experimentado la vida fuera del régimen militar, es retadora. Como elementos clave para resolver la vida cotidiana y la organización han incorporado la disciplina, el compromiso y la responsabilidad frente a los deberes; han aprendido a mediar sus diferencias sin tener que contar con alguna línea de mando que intervenga.

Al realizar el tránsito a la legalidad, las responsabilidades se concentran en el apoyo logístico para la instalación del espacio territorial, las relaciones políticas con las organizaciones que se vinculan a la implementación del Acuerdo de Paz y la participación en procesos de formación. En este sentido, se pasa de ser un guerrillero a un estudiante, lo cual reclama compromiso y esperanza. Adicionalmente, algunas prácticas que antes estaban lejos de la imaginación y de la realidad, como la interacción y el diálogo sin armas entre guerrilla, ejército y policía, son una realidad. En relación con lo anterior, la Defensoría del Pueblo (2017) afirma que los excombatientes tienen ciudadanía plena y, con ello, derecho a transitar libremente por el territorio colombiano; no están obligados a estar en los espacios territoriales. Esto significa que el proceso de reincorporación se está dando tanto en estos espacios como fuera de ellos.

También han aprendido y desaprendido hábitos individuales y colectivos, como los tiempos de vigilia y de descanso, de organización de tareas y operaciones, de cuidado y protección del grupo, de mantenimiento de campamentos y para la formación política. Para el momento en que se realizó el estudio, incluían dentro de sus actividades cotidianas la formación 
en economía solidaria, alfabetización, cuidado de la salud, generación de ideas para proyectos productivos, manejo financiero y desarrollo económico territorial. Así mismo, dedicaban mayor tiempo a la interacción social y se interesaban por el autocuidado como una práctica fuera de la supervivencia en el escenario de la guerra, reconociendo sus dolores, sus cuerpos y sus necesidades de salud física y mental.

En cuanto a los roles y la participación política de los excombatientes del espacio territorial, se amplía y se le da mayor relevancia a la participación de las mujeres. El enfoque de género incluido en los acuerdos $^{7}$ ha permitido reforzar la necesidad de la voz femenina en las dinámicas de los espacios territoriales y en los planteamientos políticos, de cara a los procesos sociales que se van a liderar en los territorios. Dentro de los roles que actualmente asumen las excombatientes se incluye el de ser delegadas con responsabilidades de dirección en el naciente partido político. No obstante, algunas mujeres expresan que, durante su vinculación al grupo guerrillero, permanentemente se les asignaban tareas de cuidado, provisión de protección y elaboración de alimentos, así como los lugares privados; consideran que esto respondía al hecho de ser mujeres y que es parte de la historia del colectivo guerrillero reconocer que predominaba la hegemonía masculina. Otras refirieren que, en el marco del conflicto, había mujeres comandantes y líderes de escuadra; si bien la dinámica patriarcal era dominante, emergían necesidades de igualdad, en términos de que estaban en combate y en la confrontación armada.
En lo que se refiere a la idea de familia, los excombatientes expresaron vagamente sus ideas o intenciones de asumirse en roles como padres o madres, conformar hogares y proyectar la vida en pareja como nuevas apuestas afectivas. Dicho esto, investigaciones como la de Flórez (2018) dan cuenta de que los lazos familiares de la población excombatiente están principalmente dados sobre su representación como colectivo y que el sentido de pareja y de familia tradicional es aparentemente reciente, esto en razón al tiempo de permanencia y la doctrina en la militancia guerrillera. Así mismo, según sus relatos, las interacciones, comunicaciones o vínculos con sus familias de origen se debilitaron como consecuencia de su ingreso a la guerrilla. Luego de la desmovilización, muchos exguerrilleros cuentan principalmente con el apoyo y la familiaridad de sus compañeros de frente, no de sus familias consanguíneas.

En cuanto a otros roles y tareas, mencionan que para poder desempeñar las actividades propias de la militancia eran muy importantes la provisión de armamento y alimentos, así como garantizar condiciones de salud adecuadas. Para ello, contaban con equipos humanos y tecnológicos que podían movilizar e improvisar ranchos para la atención específica. Creen en un enfoque de salud basado en la prevención de enfermedades tropicales, que entienden por tener dominio y conocimiento del territorio. Acuden a prácticas de medicina ancestral y campesina.

\footnotetext{
${ }^{7}$ En el marco del proceso de paz se creó una Subcomisión de Género coordinada por María Paulina Riveros, por parte del Gobierno Nacional, y Victoria Sandino, por parte de las FARC-EP. Los ejes temáticos de esta subcomisión resaltan el papel de las mujeres y de las personas con diversidad de género, así como la necesidad de garantizar sus derechos desde perspectivas igualitarias y participativas (de la Calle, 2019).
} 
Al respecto, Orjuela (2017) refiere que los grupos guerrilleros contaban con profesionales en salud y con equipos sencillos; conocían de medicamentos; implementaban métodos anticonceptivos, procedimientos de baja complejidad a nivel odontológico y de cirugía general en atenciones especializadas; generaban alianzas solidarias con la comunidad y así sorteaban situaciones de salud. En ese sentido, el cuidado y la atención en salud son parte de las preocupaciones que refieren en el espacio territorial, pues consideran que estando en el colectivo guerrillero era mucho más fácil acceder a una atención inmediata y a procedimientos sencillos. Comprenden que ahora, al ser parte de la sociedad civil, sus derechos y deberes en salud se dan en el marco de Sistema General de Seguridad Social y deben experimentar sus tensiones en términos de accesibilidad, oportunidad y asistencia. Si bien dicen reconocer que esta compleja situación es una realidad para los habitantes de zonas rurales, como Vista Hermosa, no la habían experimentado de manera personal.

\section{La participación política legal como horizonte ocupacional posible}

Ocuparse y participar significa llevar a cabo cierto tipo de actividades, teniendo en cuenta recursos, experiencias personales y contextuales que guían, motivan y orientan el hacer en la vida. Ahora bien, para abordar la participación política legal como un horizonte ocupacional actual para los excombatientes de las FARC-EP, vale la pena retomar que ellos han expresado que sus intereses de participación han estado movilizados, principalmente, de manera colectiva. Según los aportes de Cetina et al. (2017), el sentido de las actividades realizadas por los grupos de excombatientes gira principalmente alrededor de estar y hacer juntos, de emprender prácticas ocupacionales colectivas que se enmarcan en los cinco componentes que se muestran en la figura 5.

Teniendo en cuenta la propuesta de estos autores (figura 5), se retoma lo desa-

Figura 5. Esquema ocupaciones colectivas.

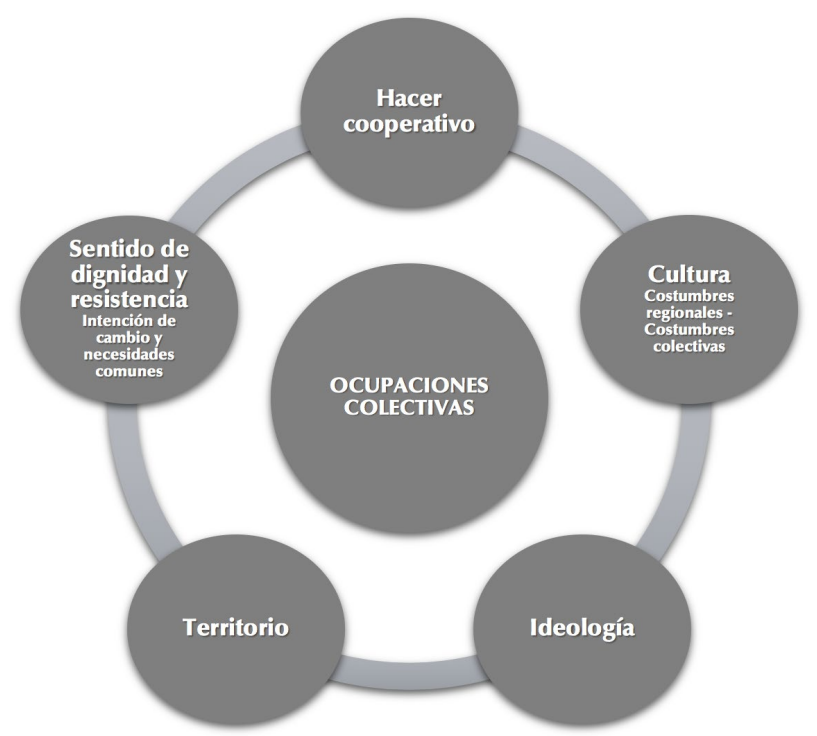

Fuente: adaptado de Cetina et al. (2017). 
rrollado en el componente de ideología (subrayando que todos los componentes actúan en función de un sistema), dado que en él se resalta todo aquello que tiene que ver con las ideas, las creencias y los sentires que enmarcan toda acción/ ocupación del colectivo. Allí figuran la justicia social, la dignidad humana, el trabajo popular, la resignificación de las relaciones, la democracia, la defensa de los derechos, la economía solidaria y la participación política. En ese sentido, es pertinente señalar que las relaciones entre las FARC-EP y el Estado han estado marcadas por una permanente tensión $y$, de acuerdo con los relatos de los excombatientes, esas disputas estuvieron motivadas por el territorio, las injusticias sociales y la explotación del campesinado. De otro lado, antes de los acuerdos, el Estado reconoció a las FARC-EP como un actor armado, pero no como actor político cuya representación y acción se centraba en el campesinado y en el territorio rural.

En línea con lo anterior y según lo refiere el líder del espacio territorial, la ideología de justicia social propuesta por las FARC-EP en sus orígenes es columna vertebral para el colectivo y, en ese sentido, pensar en la participación política los recoge a todos. Así, en el proceso de paz ha sido fundamental resaltar que democratizar, dar lugar, voz y voto a las intenciones y representaciones de los exguerrilleros se hace en el marco de la propuesta del partido FARC, desde la participación política legítima y legal como actores de la sociedad colombiana. En esa medida, como lo señala el punto dos del Acuerdo, se contempla la participación política con apertura democrática para construir la paz, permitiendo que surjan nuevas fuerzas en el escenario político para enriquecer el debate alrededor de los problemas nacionales y, así, fortalecer el pluralismo con garantías para la contribución y la inclusión política (Gobierno Nacional y FARC-EP, 2016).

Lo anterior, según los relatos de los excombatientes, significa una nueva forma de participación ocupacional, pues en sus actividades actuales dedican un tiempo importante a la deliberación y la discusión sobre la conformación y las perspectivas del partido político, lo que expresa su interés por involucrarse en la vida civil y ciudadana con prácticas de movilización social que se sumen al ejercicio de representación en el Congreso de la República. Lo anterior implica recoger la experiencia comunitaria y consolidar acciones en los territorios; adquirir nuevos conocimientos y experiencias (distintas a la confrontación); explorar habilidades; generar nuevas interacciones; participar en prácticas civiles para el desarrollo rural y social. Con el partido, afirman también, se consolida la libertad de expresión y la desaparición de la violencia política, generando una nueva posibilidad de estar en el mundo.

Lo anterior es congruente con los resultados de otras investigaciones que postulan que para el proceso de transición de excombatientes a la vida civil es fundamental escuchar sus voces e historias y reconocer las formas en las que se ha dado la vida después del conflicto, ya que esto podría permitir un mayor éxito en sus procesos de reincorporación (Kaplan y Nussio, 2018; Báez et al., 2019; Mouly et al., 2019; Rivas et al., 2019). Estos estudios advierten la importancia de contar con programas de reintegración que contemplen la naturaleza situada de los escenarios posteriores al conflicto y la urgente necesidad de intervenciones basadas en evidencia 
que recojan de manera integral factores relacionados con la exposición a la violencia, así como las demandas reales de las personas y los territorios.

Estas investigaciones también han referido que los programas a nivel comunitario para la reintegración de excombatientes en la sociedad se basan en la teoría de que la participación en sus comunidades puede promover la reconciliación y minimizar la reincidencia en actividades ilegales. Los excombatientes en comunidades más participativas tienden a atravesar con mayor facilidad la reintegración social.

Con esto, la participación política de las FARC se representa en que, como colectivo, pasaron de ser las Fuerzas Armadas Revolucionarias de Colombia - Ejército del Pueblo (FARC-EP), la guerrilla más antigua y potente de América Latina, a ser el partido Fuerza Alternativa Revolucionaria del Común (FARC). Según Melamed (2018), dicha participación política es trascendental en términos de poner fin al conflicto, porque permite darle una naturaleza política a las inconformidades que fundamentaron la conformación y consolidación de las FARC-EP y las reconoce, ahora, como interlocutor y contendor político legítimo. En esa medida, asumirse en roles socialmente aceptados implica un compromiso y una tensión consigo mismos, pues significa una reconfiguración identitaria y un reto para la sociedad civil, pues las versiones de quiénes eran y por qué hacían lo que hacían son controversiales, lo que implica un desafío aún mayor en el sostenimiento de la paz, que no solo depende de este colectivo, sino de las garantías estructurales que provea el Estado.

\section{Discusión}

El proceso de paz significa oportunidades, tal y como lo expuso Cortés (2016), es un proceso de circunstancias favorables para la vida en libertad, el acceso a los derechos, la participación agenciada desde la comunidad; no obstante, este panorama se muestra ambicioso para una sociedad que no reconoce claramente que el cese de la confrontación armada es solo una de las expresiones de la paz y que los excombatientes no son los únicos responsables de su garantía y sostenibilidad. Entonces, vale la pena problematizar y preguntarse por los imaginarios de paz que han cedido al beneficio particular y aquellos basados en sistemas de exterminio del que se considera enemigo. Este es un momento crucial del proceso, pues, seguramente, luego de la dejación de armas y con el panorama despejado por este hecho, se interpela sobre las situaciones de vida, las oportunidades y la justicia social en todo el territorio colombiano, principalmente en el rural.

En ese sentido, tal como se ha expuesto, identificarse con la paz significa reconfigurar la versión de sí mismo, encontrarse con los sentimientos propios de transformación y esperanza en medio de preguntas e incertidumbres y del ejercicio político y colectivo, desde cualquier lugar y condición ciudadana. Para los excombatientes será un reto, pues ¿qué tan fácil es para la sociedad colombiana transitar a la inclusión social basada en el perdón, con la mirada justa y crítica del conflicto? Puede que para las zonas rurales, tal como lo afirman Mouly et al. (2019), sea más fácil acercarse y acoger a la comunidad excombatiente, pues, como lo muestra la historia, la guerrilla de las FARC repre- 
sentó en algún momento los intereses y necesidades de los campesinos.

No obstante, según Valdés (2017), el papel de los territorios urbanos en el proceso de paz parece no ser tan claro, lo que plantea retos importantes, entre ellos, transformar y mejorar las relaciones entre áreas rurales y urbanas, desarrollando proyectos conjuntos que permitan superar la segregación cultural, espacial, económica y social, sumado al desafío de formular e implementar políticas públicas para enfrentar, por ejemplo, la demanda urbana de recursos naturales que ha tenido que sostener forzadamente la ruralidad. En este sentido, esta podría ser una oportunidad para dinamizar y consolidar otras economías, basadas en la actividad agrícola. También se considera un reto la creación de mecanismos intersectoriales para fortalecer lo público, lo colectivo y los bienes comunes. Ahora bien, ¿el tránsito a la participación en la vida civil y política de los excombatientes se da de la misma forma en todo el territorio colombiano? Este interrogante surge a partir de esta experiencia investigativa y anima a seguir complejizando y comprendiendo la realidad del proceso de paz.

Entre tanto, para la vida de los excombatientes es un desafío transitar a la normalidad, a la cotidianidad del mundo civil, si solo cuentan con ellos mismos, pues si bien ha sido claro que el colectivo es esencial en su organicidad y que los espacios territoriales han contado con el apoyo de organizaciones no gubernamentales, organizaciones campesinas, universidades y entidades internacionales (cartografía social, agosto 20 de 2017), la sostenibilidad depende de importantes circunstancias basadas en la confianza y la concreción de los acuer- dos. Esto significa que es preciso contar con los recursos políticos, jurídicos, económicos y humanos para lograr procesos exitosos de reincorporación social, como parte de la responsabilidad del Estado de garantizar a los excombatientes y a la sociedad colombiana en general un verdadero proceso de paz.

La participación política legal del partido FARC, como horizonte ocupacional, adquiere una especial y trascendental relevancia. Pasar de ser una organización armada a un colectivo político con apuestas por la legitimidad de sus acciones en el marco de la legalidad y la aceptación social no solo permite el reconocimiento de la colectividad, también dinamiza la democracia del país, ofreciendo otra opción de participación desde la pluralidad de intereses y necesidades de las personas y los territorios. Es un camino que inicia con grandes expectativas para los excombatientes y para el resto de la sociedad, pues significa creer a pesar de la memoria de eliminación violenta de un grupo similar (Unión Patriótica), cuando transitaba hacia la participación política posterior a un acuerdo, y de la larga historia de conflicto y violencia agenciada por grupos guerrilleros.

\section{Conclusiones}

Las transformaciones ocupacionales a las que se enfrentan los excombatientes son retadoras, pues si bien los espacios territoriales de capacitación y reincorporación son un importante esfuerzo, dichas transformaciones se expresan en la cotidianidad, en donde se construyen las formas de hacer las cosas y de interactuar. Resulta evidente que solo serán realmente posibles si existen oportunidades y experiencias estructurales que 
dinamicen nuevas comprensiones sobre las formas de estar en el mundo, lo que hace urgente la implementación de los acuerdos, las garantías y el soporte político, administrativo y social, así como la consolidación de datos demográficos y de caracterización de las personas y los territorios.

El grupo guerrillero más antiguo de América Latina, luego de un proceso de diálogo con el Gobierno colombiano, reconoce que su ocupación insurgente puede ser transformada hacia una socialmente aceptada y legítima, desde el ejercicio democrático y de participación política legal. Es un camino por recorrer que requiere garantías, una oportunidad para recomponer las formas violentas en las que se dieron sus prácticas políticas, asumiendo sus responsabilidades en el marco de la Jurisdicción Especial para la Paz $(J E P)^{8}$ y desafiando, a su vez, la po-

\section{Referencias}

Alcaldía de Vista Hermosa, Corporación Desarrollo para la Paz del Piedemonte Oriental - CORDEPAZ, Fondo de Población de las Naciones Unidas - UNFPA y Universidad Externado de Colombia (2014). Municipio de Vista Hermosa. Avances diagnóstico territorial. Programa de asistencia técnica y formación activa de expertos locales en población y desarrollo para la revisión y ajuste de planes de ordenamiento territorial. http:// vistahermosameta.micolombiadigital. gov.co/sites/vistahermosameta/content/ larización y la división política del país para transitar hacia la paz.

Una de las limitaciones de este estudio de caso fue el tiempo que duró la visita, pues resultó escaso para desarrollar en profundidad una propuesta investigativa participante.

Agradecimientos. A los integrantes del Espacio Territorial de Capacitación y Reincorporación Georgina Ortiz por su disposición, su diálogo abierto, la hospitalidad durante nuestra estadía y la posibilidad de intercambiar sueños y caminos posibles de paz. A los semilleros de investigación Diversitas y Ocuparte de la Escuela Colombiana de Rehabilitación por el interés, la discusión y las acciones que hicieron posible la visita al espacio territorial, y por compartir esta experiencia en diferentes escenarios de construcción social. files/000023/1128 diagnostico-territorial vistahermosa.pdf

Alcaldía de Vista Hermosa-Meta (s.f.). Municipio. Geografía. Consultado en enero de 2020. http://www.vistahermosa-meta.gov. co/municipio/geografia

Alvarado, S.V. (2016). A cada vuelta de siglo... este deseo de paz. En S.V. Alvarado, E. A. Rueda y P.Gentili (eds), Paz en Colombia: perspectivas, desafíos, opciones (pp.25-35). Clacso. http://biblioteca.clac-

\footnotetext{
${ }^{8}$ Es el componente de justicia del Sistema Integral de Verdad, Justicia, Reparación y no Repetición creado por el Acuerdo de Paz. La JEP tiene la función de administrar justicia transicional y conocer de los delitos cometidos en el conflicto armado antes del 1 de diciembre de 2016. La JEP fue creada para garantizar los derechos de las víctimas a la justicia, ofrecerles verdad y contribuir a su reparación, con el propósito de construir una paz estable y duradera.
} 
so.edu.ar/clacso/se/20160930124934/

Paz en Colombia.pdf.

Álvarez, A. (2017). Acuerdos y construcción de paz en Colombia: retos a la gobernabilidad y la cultura de paz. Prospectiva. Revista de Trabajo Social e intervención social. 24. 13-45. https://doi.org/10.25100/ prts.v0i24.5872

Asamblea Nacional Constituyente (1991). Constitución Política de la República de Colombia. Gaceta Constitucional $N^{\circ}$ 116. http://www.secretariasenado. gov.co/senado/basedoc/constitucion politica 1991.html

Báez, S., Santamaría-García, H. e Ibáñez, A. (2019). Disarming ex-combatants' minds: Toward situated reintegration process in post-conflict Colombia. Frontiers in Psychology, 10, 73. https://doi.org/10.3389/ fpsyg.2019.00073

Centro Nacional de Memoria Histórica (2013). ¡BASTA YA! Colombia: Memorias de guerra y dignidad. Imprenta Nacional. http://www.centrodememoriahistorica. gov.co/descargas/informes2013/bastaYa/ basta-ya-colombia-memorias-de-guerra-y-dignidad-2016.pdf

Cetina, K., Rivera, C. y Rodríguez, P. (2017). Reconociendo las ocupaciones colectivas como aporte para la paz: diálogo de saberes con comunidades del Pacífico colombiano [Trabajo de grado de pregrado, Universidad Nacional de Colombia]. Repositorio Institucional UN. http://bdigital.unal.edu.co/74633/1/PaulaAndreaRodr\%C3\%ADguezSotelo.2017.pdf

Christiansen, C. H. (1999). Defining lives: Occupation as identity: An essay on competence, coherence, and the creation of meaning. American Journal of Occupa- tional Therapy, 53(6), 547-558. https:// doi.org/10.5014/ajot.53.6.547

Cortés, F. (2016). La guerra y la Paz. En S.V. Alvarado, E. A. Rueda y P.Gentili (eds), Paz en Colombia: perspectivas, desafíos, opciones (pp.37-43). Clacso. http://biblioteca. clacso.edu.ar/clacso/se/20160930124934/ Paz en Colombia.pdf

de la Calle, H. (2019). Revelaciones al final de una guerra: testimonio del jefe negociador del Gobierno colombiano en La Habana. Penguin Random House.

Defensoría del Pueblo (2017). Informe Espacios Territoriales de Capacitación y Reincorporación. Reincorporación para la paz. Defensoría del Pueblo. https://www. defensoria.gov.co/public/pdf/Informe ETCR.pdf

Díaz, L. B. (2015). Nuevas configuraciones del derecho a la paz. Misión Jurídica, 8(9), 259-277. https://revistas.unicolmayor.edu.co/index.php/mjuridica/article/ view/442/800

Equipo Humanitario Colombia (18-19 de abril, 2016). Informe Final MIRA: Veredas La Argentina, La Cooperativa y Piñalito - Municipio de Vistahermosa (Meta). OCHA. https://assessments.hpc.tools/sites/default/ files/assessments/informe final mira vistahermosa_vf.pdf

Flórez, L. (2018). Reconstrucción de redes sociales en excombatientes de las FARC-EP [Trabajo de grado de pregrado]. Facultad de Ciencias Sociales y Política. Fundación Universitaria Católica Lumen Gentium.

Fuerzas Armadas Revolucionarias de Colombia - FARC-EP (s.f.a). ¿Qué es la conferencia nacional de guerrilleros?. http:// 
www.farc-ep.co/octava-conferencia/ que-es-la-conferencia-nacional-de-guerri$\underline{\text { leros.html. }}$

Fuerzas Armadas Revolucionarias de Colombia - FARC-EP (s.f.b). Estatuto FARC-EP. Conferencia Nacional de Guerrilleros. https://www.farc-ep.co/octava-conferencia/ estatuto-farc-ep.html

Gobierno Nacional y FARC-EP (2016). Acuerdo final para la terminación del conflicto y la construcción de una paz estable y duradera. https://www.cancilleria.gov. co/sites/default/files/Fotos2016/12.11 1. 2016nuevoacuerdofinal.pdf

Instituto Distrital de la Participación y Acción Comunal - IDPAC (2019). Acciones para construir la paz en los territorios. Escuela de Participación. http://escuela.participacionbogota.gov.co/Recursos/construcciondepaz/modulo1/leccion 1v4/ procesos-de-paz.html

Kaplan, O. y Nussio, E. (2018). Community counts: The social reintegration of ex-combatants in Colombia. Conflict Management and Peace Science. 35(2), 132-153. https:// doi.org/10.1177/0738894215614506

Medina, C. (2010). FARC-EP y ELN. Una historia política comparada (1958- 2006) [Tesis doctoral, Universidad Nacional de Colombia]. Repositorio Institucional UN. http://www.bdigital.unal.edu. co/3556/1/469029.2010.pdf

Melamed, J. (2018). Participación política de las FARC-EP y apertura democrática para la construcción de la paz en Colombia: una aproximación esquemática. Revista Izquierdas. 39. 86-109. https://scielo.conicyt.cl/pdf/izquierdas/n39/0718-5049-izquierdas-39-86.pdf
Moreno, F. (2014). El concepto de paz en la Constitución Política de Colombia de 1991: reconstrucción dialéctica de su significado a partir de la jurisprudencia de la Corte Constitucional. Revista de Derecho Universidad Católica del Norte, 21(2), 305-346. http://dx.doi.org/10.4067/ S0718-97532014000200009.

Mouly, C., Hernández-Delgado, E. y Giménez, J. (2019). Reintegración social de excombatientes en dos comunidades de paz. Revista Análisis Político. 32(95). 3-22. https://doi.org/10.15446/ anpol.v32n95.80822

Orjuela, J. (2017). La salud pública en el tránsito de la guerra a la construcción de la paz en el municipio de la Macarena [Tesis de maestría]. Repositorio Institucional Pontificia Universidad Javeriana. https://repository.javeriana.edu.co/hand$\underline{\text { le/10554/37928 }}$

Palacios, M. (2016). Investigación acción participativa respecto a ocupaciones colectivas y territorio con jóvenes transgresores. Revista Terapéutica, ciencia, tecnología y arte, 9, 15-20. http://www.uspsantapaula. com/inicio/boletines/revista-terapeutica/ revista-terapeutica-0616.pdf

Peñas, O. L., Gómez, A. M. y Parra, E. I. (2015). Participación de terapia ocupacional en contextos de conflicto armado y postconflicto. Revista de Salud Pública, 17, 612-625. http://dx.doi.org/10.15446/rsap. v17n4.53047

Prada, M.P., Sánchez, M., Restrepo, I. y Arboleda, Z. (2017). Acción CaPAZ. Estrategia de capacidades para la paz y la convivencia. OACP, DNP, ESAP, DAFP.

Rivas, M., Garzón, K. y Shakespeare, T. (2019). Social participation and in- 
clusion of ex-combatants with disabilities in Colombia. Disability and the Global South. 6(2), 1736-1755. https://disabilityglobalsouth.files.wordpress. com/2019/07/06 02 03.pdf

Sanabria, L. y Rubio, S. (2011). Ocupación como proceso subjetivante. En C. Rojas (ed.), Ocupación: sentido, realización y libertad. Diálogos ocupacionales en torno al sujeto, la sociedad y el medio ambiente (pp.71-104) . Universidad Nacional de Colombia.

Sector de Conocimiento y Aprendizaje, Banco Interamericano de Desarrollo (2011). Pautas para la elaboración de Estudios de Caso. BID. https://publications. iadb.org/publications/spanish/document/ Pautas-para-la-elaboración-de-estudios-de-caso.pdf

Uscatescu, J. (2001). La cotidianidad. Investigaciones fenomenológicas: Anuario de la Sociedad Española de Fenomenología, (3). 211-224. https://doi.org/10.5944/ rif.3.2001.5426
Valdés, M.F. (ed). (2017). Ciudades sostenibles en el posconflicto en Colombia: Cartagena, Bogotá, Medellín, Bucaramanga. Foro Nacional Ambiental y Fescol. http://www.foronacionalambiental. org.co/wp-content/uploads/2017/07/ Ciudades-sostenibles-en-el-postconflicto-Colombia.compressed.pdf

Villamizar, D. (2018). Las guerrillas en Colombia. Una historia desde los orígenes hasta los confines. Debate.

Villarraga, A. (ed.). (2015). Seminario: Los procesos de paz en Colombia: experiencias y propuestas desde las ciudades regiones. Fundación Cultura Democrática. https://biblioteca.ucp. edu.co/Descargas/CORE/documentos/1.pdf 